\title{
Chinese business negotiations: South African firm experiences and perspectives
}

\author{
F. Horwitz*, R. Hemmant and C. Rademeyer \\ Graduate School of Business, University of Cape Town, \\ Private Bag X3, Rondebosch 7701, Republic of South Africa \\ fhorwitz@gsb.uct.ac.za
}

Received March 2008

\begin{abstract}
South African business joint ventures in China are increasing. Successful negotiations are a key component when establishing a gateway into the Chinese market. This research is undertaken to establish South African business negotiators' understanding of Chinese business negotiation styles and behaviours and determinants of cross-cultural negotiation. Primary data was obtained through quantitative ranking style questionnaires and semi-structured interviews with selected South African business people who have had business negotiations with Chinese firms. The research revealed that perceptions held by South African business negotiators do not differ substantially from that of Westerners with regards to aspects such as trust relationships, hierarchical decision making, long-term decision making, networks and the concept of 'face'.
\end{abstract}

*To whom all correspondence should be addressed.

\section{Introduction}

China is one of the world's largest emerging markets, with a total population of 1.3 billion people in 2002 (World Bank Group, 2002). The Chinese economy has grown rapidly over recent years, reporting an annual GDP of approximately 8\%. In 2003 China overtook the USA as the country with the largest influx of foreign direct investment (Organization for Economic Co-Operation and Development, 2003). China provides significant market potential with increasing numbers of South African (SA) firms now having operations and growing market share in mainland China, including Khumba Resources (iron ore), SAB Miller, Naspers, Sasol, Anglo American and other large mining sector firms. South Africa is China's main trading partner in Africa accounting for 21 per cent of the China-Africa trade total and with over 23 per cent annual trade growth between China and South Africa (Davies, 2004). Trade between China and Africa amounted to US\$ 55 billion in 2006. China has set a trade target of US\$ 100 billion with Africa by end 2010 (Davies, 2007). South Africa risks missing out on China's economic revolution unless greater knowledge and understanding of China and its people occurs (Davies, 2007:20).

Doing business with and in China is complicated by strong differences in culture that exist between China, the Western world and other emergent market economies like SA. China is home to one of the oldest civilizations that are underpinned by philosophies foreign to the Western world (Fang, 1999). Academic literature has documented the difficulty of doing business in China (Bates \& Adams, 2003) and of negotiating with Chinese organisations. But China is rapidly increasing its economic penetration in Africa. too. It is estimated that there are over 800 Chinese state-run enterprises operating in sub-Saharan Africa
(Christianson, 2006). Cultural differences are seen as one of the greatest reasons for negotiation failure (Fang, 1999). In order to increase the chances of successful business negotiations in China, it is important that SA firms understand the negotiation styles and behaviors of their Chinese counterparts and foster sensitivity to cultural differences and strategically driven negotiating approaches (Van der Wath, 2004). Adherence to these should increase the prospect of successful negotiations with Chinese business people.

\section{Literature review}

\section{Negotiation strategies and cultural impacts}

Lewicki, Saunders, Minton and Barry (2003) refer to two negotiation processes - symbiosis and predation. Fang labels them as cooperation and competition respectively (Fang, 1999). The cooperative/symbiosis approach is underpinned by the theory of social exchange (Fang, 1999). This approach is characterised by the importance placed on open communications, identifying underlying interests driving different positions, the value placed on maintaining relationships and attainment of mutual gain solutions (Anderson, 1992). The competitive approach does not view fostering of relationships as a priority. This negotiation process is characterized by a power-based negotiation style rather than an interest-based negotiation style (Anderson, 1992). The final outcome normally has a clear winner and loser. Culture can be viewed as "a set of shared and enduring meanings, values, and beliefs that characterise national, ethnic, or other groups" (Martin, Mayfield, Mayfield \& Herbig, 1998:342). International business negotiations are effected by different cultural dimensions brought to negotiations. Participants in cross-cultural 
negotiations do not necessarily share the same assumptions, mental models and ways of thinking and behaving (Woo \& Prud'homme, 1999; Sheer \& Cheng, 2003). To be unaware of these different mental models will inevitably lead to misunderstandings, miscommunications (Martin et al., 1998) and eventually failed negotiations. During crosscultural negotiations, the each party may bring a different worldview or mental model referred to by Ting-Toomey (1992) as cognitive constraints, a different conceptualisation of the negotiation process (script constraints, see Kumar \& Worm, 2003) and a different set of behaviours. Chinese culture varies greatly from that of Western cultures (Gesteland, 1997). This translates into different negotiation styles and behaviour, which results in sometimes difficult negotiation experiences between Westerners and Chinese. Confucian philosophy and Chinese stratagems shape a Chinese way of doing business and negotiation styles (Fang, 1999).

The particular characteristics and realities of the Peoples Republic of China, such as the geographical size of the country and its population, the communist regime, the absence of a human rights system, the rapid economic changes the people are exposed to, as well as bureaucratic aspects that infiltrate politics, economic planning and the legal framework influence the behaviour the Chinese people (Fang, 1999). This explains the Chinese negotiator's fear of taking risk and making mistakes (Miles, 2003). It partly explains why they attempt to avoid decision-making and taking on responsibility (Fang, 1999). The Chinese philosophy of Confucianism has influenced Chinese behaviour for centuries (Sheer \& Chen, 2003). A number of core Confucian values or principles influence the negotiation behaviour of Chinese business people (Sheer \& Chen, 2003; Fang, 1999). The first such principle is the presence of moral ethics, which serves as the foundation of Confucianism. There is often a high degree of distrust of outsiders especially of the family group. More value is placed on building relationships or social capital than on legal rules (Staber, 2006). Confusion philosophy does not see the legal system as the preferred mechanism to regulate behaviour and solve problems. Conversely, the individual is trusted to regulate his own moral behaviour. Shame and face are two critical devices to ensure that the individual self regulate his behaviour (Poulson, 2000; Ting-Toomey, 1999).

Confucianism places great value on interpersonal relationships. These interpersonal relationships are characterised by the following important concepts: Guanxi A network of personal relationships that forms the basis of mutual interactions (Fang, 1999). Guanxi is defined as "a special relationship individuals have with each other in which each can make unlimited demands on the other" (Fang 1999:118). Guanxi is characterized by the notion of "reciprocal obligations" and is prominent in Chinese business processes; necessary in order to get things done and having access to resources (Coggin \& Coggin, 2001; Woo \& Prud'homme, 1999). Confucianism encourages respect for hierarchy and status (Miles, 2003). The right to voice one's opinion is linked to hierarchical position, seniority, status, expertise and authority. Fang (1999) notes that the status of the foreign negotiator will have a direct influence on the attitude of the Chinese counterparts and the seriousness of the negotiations. An important Confucian principle is the need for social harmony in relationships (Sheer \& Chen, 2002). The Chinese avoid making direct challenges to ideas and passing judgement on opinions, as this will threaten the harmony of interpersonal relationships (Fang, 1999; TingToomey, 1992). This can make it more difficult for Western negotiators to establish the needs and interests that underpin negotiation positions. They seem to seek compromise and cooperation when solving conflicts. The loss of face extends beyond the individual and also has a detrimental impact on the social networks within which the individual operates. It is thus important to take steps to protect ones "face" (known as saving face) (Tan \& Lim, 2003). It is important to give face to other people through showing respect to the other person and recognising the other person's status and reputation (Buttery \& Leung, 1996). Being overly critical of a Chinese counterpart and his suggestions could cause face to be lost and threaten harmony between the parties (Fang, 1999; Woo \& Prud'homme, 1999). Foreign negotiators should give face to their Chinese counterparts by providing renquin (reciprocity in relations) and should strive to avoid actions that destroy face. Chinese negotiators are well prepared and focused on detail. This can be explained in terms of the fear of losing face in the event of being made aware of mistakes.

\section{Negotiating stratagems}

The Chinese people have earned a reputation as tough negotiators who have mastered the art of negotiating. Chinese culture has a strong strategic component called $j i$ referred to by Fang 1999, as stratagems). The concept of $j i$ was first introduced more than two millennia ago by the Chinese military strategist Sun Tzu in his treatise the Art of War. According to Guari and Fang (2001), ji or the Chinese stratagems is more than a list of strategies, tricks and ploys, but is rather a collection of Chinese wisdom and a framework through which challenging situations can be assessed and addressed. Apart from Sun Tzu's treatise, another work Secret Art of War: The Thirty Six Stratagems also document the strategic component of Chinese culture. These stratagems are embedded in Chinese culture and are passed down from generation to generation through parents, schools and the media. At the heart of all the stratagems is the idea to "subdue the enemy without fighting" (Ghauri \& Fang 2001:9). Within a business negotiation context, these stratagems are used to "bargain without bargaining" (Fang, 1999:182). The stratagems provide Chinese negotiators with a competition-orientated negotiation strategy where the aim is to win as much as possible at the expense of the counterpart. This is directly opposite to the more cooperative approach to negotiation strategy promoted by the Chinese philosophy of Confucianism (Ghauri \& Fang, 2001). Fang posits that Chinese business negotiators use shrewd tricks and strategies in situations where they do not have a strong trust relationship with their negotiating counterpart. In terms of the Confucianism principle of reciprocity, it would be morally acceptable to use dirty tricks against negotiators that are unfair, inconsiderate or untruthful. Foreign negotiators are advised to attempt to move Chinese negotiators away from a competitive negotiation approach to a cooperative approach by 
establishing a strong trust relationship in the pre-negotiation phase (Fang, 1999).

Western negotiators may find Chinese negotiators highly conscious of status placing great importance on hierarchy. This manifests itself in the Chinese negotiators being only willing to only negotiate with people of the same or higher hierarchical level (Woo \& Prud'homme, 1999). In cases where interpreters are used, it is important to look at the principal when speaking and not the interpreter (Sheer \& Chen, 2003), again acknowledging the status of the individual. Some research shows that face can be used as a strategic negotiation tactic (Hutching, 2003). Network relationships are very important (Hutching, 2003). Foreigners receive different treatment once they have been accepted into a family/friendship network, and thus, establishing a friendship network is highly important for any successful business negotiation (Woo \& Prud'homme, 1999). This enables business transactions to get done more speedily, and it is also the easiest (and often the only) way to obtain access to further business opportunities (Woo \& Prud'homme, 1999). However there is a perception that the Chinese have a high distrust of foreigners, specifically Westerners (Hutching, 2003). A foreigner will only be accepted within the Chinese family/friendship network if the Chinese counterpart is sure that the person can be trusted. Trust is earned over a long period of time, which requires much effort and patience (Hutching, 2003; Kumar \& Worm, 2003). Lengthy pre-negotiation phases can be used to earn this trust and respect - the notion of building social capital. Chinese negotiators are interested in developing a personal relationship with the negotiation counterparts, rather than a relationship with the foreign firm (Sheer \& Chen, 2003). As a result, they want to get acquainted with their counterpart, building long-term relationships based on mutual trust (Fang, 1999).

Chinese contract and intellectual property law is still seen as inadequate by Western business people, despite the Chinese joining the World Trade Organisation and increasing their engagement in global trade (Graham \& Lam, 2003). Over and above the skepticism that surrounds the Chinese legal system, there also exist (negative) perceptions about the value placed on legal rules and formal contracts by the Chinese negotiator. The Chinese take verbal commitments much more seriously than written legal contracts (Kumar \& Worm, 2003), preferring the relationship to be governed by mutual trust and respect (Graham \& Lam, 2003). According to Fang, Chinese negotiators view the contract as a concrete signal of the commitment of the parties to step into a longterm relationship. These perceptions explain why the Chinese tend to renegotiate contractual issues (Fang, 1999). Fang provides three possible reasons for the tendency to renegotiate, namely a strategic reason as they attempt to wear counterparts down, a hierarchical and bureaucratic reason, as they want to ensure a good solid negotiated outcome that gives them face, and a Confucian reason that the contract is the beginning of an ongoing relationship where the parties constantly work at emerging issues. Problems, issues and concerns are renegotiated and solved through mutual cooperation (Fang, 1999).
Negotiation styles of Chinese and Westerners may differ. Westerners adopt a more linear approach, where they would break the negotiations down into a number of issues (the bargaining mix) and deal with each topic separately. Chinese negotiators are, however, comfortable dealing with various issues simultaneously, placing little emphasis on structure or bipolar cultural constructs on negotiation, rather viewing negotiations as multifaceted (Graham \& Lam, 2003; Metcalf et al., 2007). According to Woo and Prud'homme (1999), Chinese negotiators exhibit vague and ambiguous behaviour during negotiations. In order not to offend the negotiating counterpart, they would refrain from responses that reject a request or proposal. Alternatively, they would communicate their disapproval in an indirect manner, avoiding the use of explicit 'no' as an outright answer (Woo \& Prud'homme, 1999; Smith, 2000). They often avoid directly confronting and dealing with contentious issues in the hope that the issues will be sorted out at a later stage during negotiations (Taylor, 2002).

An integral part of our research is to establish whether the perceptions held by SA business negotiators of their Chinese business negotiation counterparts are similar to those as identified in this literature review. Western perceptions discussed above illustrate the complications introduced by the different cultural backgrounds of the negotiators. These different and conflicting negotiation styles are often regarded as the root cause behind cross-cultural business negotiation breakdown (Kumar \& Worm, 2003: 263; Fang, 1999). The greater the cultural incompatibility, the more difficult it is to reach successful negotiated outcomes (Sheer \& Chen, 2003). These frustrations are put into perspective when one uses studies of cultural dimensions to consider the high cultural variability that exists between Chinese culture and Western culture. Hofstede et al. (2002) propose various cultural dimensions, for example in collectivist cultures greater emphasis is placed on the family or group. The individual defines his/her role within the group. In a collectivist culture behaviour is to a large extent shaped by shame and face (Li, Wang \& Fisher, 2003). Within the individualistic cultures greater emphasis is placed on the experiences and rights of the individual. Cultures with a high uncertainty avoidance dimension have a low tolerance of ambiguity, vagueness and uncertainty (Hofstede et al., 2002). These cultures prefer clarity, legal rules and controls that reduce ambiguity. Conversely, cultures with low uncertainty avoidance traits are much more at ease with ambiguity. Cultures with a long-term orientation are much more attuned to long-term commitments and traditions than short term orientated cultures (Ting-Toomey, 1992). A culture with a strong masculine dimension is more at ease with using power and strength in order to resolve conflicts, whereas feminine cultures prefer a more integrative approach when (Hofstede et al., 2002; Ting-Toomey, 1992). Cultures which prefer to operate in terms of fixed linear schedules see time as a scarce resource and regard efficient as a priority (Gesteland, 1997). In contrast, synchronic cultures, described by Bird \& Metcalf (2003:806) as the polychromic cultures, are at ease with handling various different activities at the same time (Trompenaars \& Hampden-Turner, 1997). These cultures are less concerned with having to stick to deadlines and schedules (Gesteland, 1997). Time is not seen as a limited resource and plays 
second fiddle to the importance placed on building relationships (Bird \& Metcalf, 2003; Herbig, 2004). Western societies fit the description of a monochromic culture, because time is seen as precious and should be utilized efficiently (Miles, 2003; Gesteland, 1997). Asian cultures are generally grouped as high context cultures (Gesteland, 1997), whereas North American people are generally perceived as being of a low context culture, who are much more verbal and direct (Gesteland, 1997). Western business negotiators will tend to be focused on efficiency in negotiations, whereas Chinese negotiators tend to be more focused on the relationship with the negotiating party (Gesteland, 1997). According to Fang, Westerners seem to find the inconsistent and contradictory behaviour of the Chinese, discussed earlier in this paper, difficult to grasp (Fang, 1999). The fluctuation between a competitive style of negotiation, underpinned by shrewdness (resulting in the use of strategic tricks and ploys), and the more harmonious consensus-seeking style constitutes the contradictory behaviour (Fang, 1999). In addition, the use of strategic tricks and ploys causes great frustration amongst Westerners (O’Shea, 2002). However, Metcalf et al. (2007:164) caution against 'sophisticated cultural stereotyping'.

A stronger cultural alignment between Chinese and SA negotiators, in comparison to the weaker alignment between Western and Chinese negotiators, might result in differences in perceptions and frustrations (of the Chinese) held by South Africans and Westerners. As mentioned above, negotiations has a greater chance of success where the parties to the negotiations are more culturally aligned (Sheer \& Chen, 2003; Rijamampianina \& Maxwell, 2002). The ability to see conflict from different perspectives and to have cultural maturity such that one is culturally sensitive and adaptable, improves the chances of successful negotiations (Naranjo, 2001). South African business negotiators' experiences of living in a culturally diverse country, their exposure to a process of political transformation, reconciliation and nation-building, their increasing exposure to the African philosophy of ubuntu (self-identity through others, and collective, group decision making), and the constitutional values of dignity might have fostered a sensitivity, awareness and tolerance of cultural differences. Furthermore, SA negotiators might have been exposed to negotiating behaviour in South Africa that is not vastly different in comparison to Chinese negotiation behaviour (e.g. lengthy drawn out industrial negotiations and the synchronic attitudes towards time). Such cultural maturity and sensitivity may shape South African perceptions of Chinese business negotiation styles and behaviours leading to improved negotiation experiences.

\section{Methodology}

\section{Significance and objectives of research}

Limited academic research exists on business negotiations between SA and Chinese firms. Horwitz, Ferguson, Rivett and Lee (2005) evaluate factors important when contemplating business links with China. However, their research did not focus specifically on negotiation experiences. Thus there is a need for research that explores SA negotiators' experiences with Chinese negotiators. Such research is important for understanding Chinese negotiation styles and behavior, the difficulties arising from cross cultural interaction, and traits that may contribute to successful negotiations or hamper the process. The aims of this exploratory research are:

a) To understand the perceptions that SA business negotiators have of the negotiation behaviours of their Chinese counterparts. The main focus will be on behavioural aspects identified as foreign, problematic or hindering negotiations.

b) To compare these identified perceptions against the perceptions of Western business negotiators (as documented in academic literature), in order to determine whether a difference exists between the views and opinions held by SA and Western business negotiators' of Chinese business negotiation behaviour and style.

c) To identify frustrations experienced by SA negotiators in order to determine whether such is similar to the frustrations of Western negotiators.

d) To investigate whether any socio-political aspects of being South African are associated with greater understanding of, and sensitivity towards unique cultural dimensions of the Chinese, making negotiations easier. These socio-political factors include the exposure to SA's multicultural dimensions, the tolerance of diversity and the exposure to South African collectivist values such as the philosophy of ubuntu.

\section{Research propositions}

The following propositions are explored:

a) South African business negotiators' perceptions of Chinese negotiation styles and behaviours are different from those held by Western business negotiators.

b) South African business negotiators do not share the same frustrations as Western business negotiators when dealing with their Chinese counterparts.

c) South African socio-political factors contribute positively towards the ability of business negotiators to successfully negotiate with their Chinese counterparts.

The following limitations exist in this research: Various practical difficulties (such as time-limitations) and methodological hurdles (see Fang, 1999:11-14) resulted in us choosing not to do qualitative or quantitative research amongst Chinese negotiators. Our research therefore focuses only on a South African perspective of Chinese negotiators and not visa versa. The absence of an authoritative database of South African firms that trade with China made it difficult to establish the exact size of the target population, and thus may limit statistical significance. A convenience sampling approach was therefore used. The sample consisted mainly of white SA males. Attempts to obtain responses from black negotiators with experience in 
China proved unsuccessful. The latter might bring a different dimension to the negotiation experience with the Chinese given a more collectivist cultural orientation (Booysen, 2001). Although the collective negotiation exposure of our respondents is very high, the context of these negotiations differed. Some of these negotiation experiences were of a routine, transactional nature, where a large degree of trust between the parties is not a prerequisite. Other negotiation experiences were of a more strategic nature, aimed at securing an ongoing trust relationship (consistent with Van der Wath, 2004). One would ideally want to stratify the responses on the basis of their nature and analyse the different subgroups. However, the current population of SA business people with negotiation experience in China did not allow for such an analysis, as the subgroups would have been small in number.

\section{Data requirements and sampling}

Our first two propositions focus on SA firm negotiators' perceptions and opinions of Chinese negotiation styles and behaviours. In order to achieve this, we identified fourteen key themes that encapsulate Western negotiators' perceptions of their Chinese counterparts. These themes are discussed in our literature review and include aspects such as trust, renegotiation, respecting face, status, contractual formalities and the situational flexibility of the Chinese. This investigated whether SA firm negotiators hold similar views to that of Western negotiators (as the established literature suggests). As a result we identified at least two statements testing each of the fourteen identified themes. Associated with perceptions of SA negotiators are frustrations experienced with Chinese negotiation styles and behaviours. In order to address this aspect, part of our research survey also attempted to identify the main frustrations of SA negotiators and to compare these frustrations with those referred to in the literature. Nonprobability sampling, using the convenience sampling method (Saunders, Lewis, \& Thornhill, 2003) was the primary mechanism used to select respondents from this list. An official register of South African firms that do business in China is not available. A list of possible firms to approach was made through open source literature (including press articles) and previous SA research (Horwitz et al., 2005 and 2006). A structured questionnaire was developed using mainly ranking style questions. Respondents were also asked to mention the major lessons gained through their negotiation experiences; and three semi-structured interviews with SA business people doing business negotiations with the Chinese were conducted. The purpose of these interviews was to provide qualitative insight triangulated with findings from the structured questionnaires.

\section{Description of respondents}

Negotiators from approximately fifty SA firms with business relations in China were contacted. Thirty individuals, with 165 years of combined negotiating experience responded by completing our questionnaires. All the respondents had experience of face-to-face negotiations in China. Their negotiation experiences varied from normal transactional negotiations involving importation and exportation to more strategic negotiations aimed at establishing joint-ventures.

Sample Distribution - Nature of Negotiation

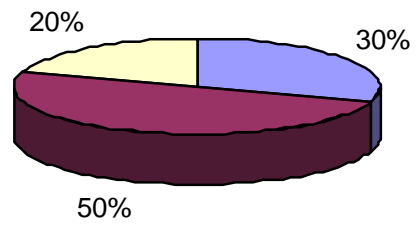

$\square \mathrm{JV}$

$\square$ Import/Export

$\square$ Other

$50 \%$

Figure 1: Sample distribution reflecting nature of negotiation

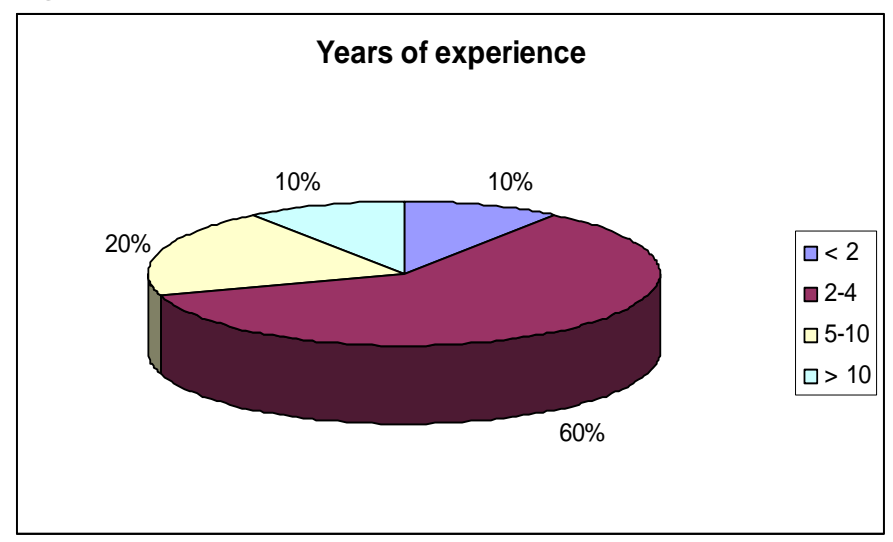

Figure 2: Respondents' years of experience in Chinese negotiations

\section{Findings}

Research propositions are each defined and a descriptive statistical analysis of the data, is given. This is followed by a discussion of the findings and conclusions. Cronbach's item reliability test was used for questions relating to propositions 1 and 3 respectively. In addition, one question (6) was also subjected to a factor analysis.

Proposition 1: South African business negotiators' perceptions of Chinese negotiation styles and behaviours are different from those held by Western business negotiators. Respondents were asked to rank the 3 statements that best describe the Chinese negotiator. Table 1 below reflects on the outcomes: 
Table 1: Ranking of statements that best describe the Chinese negotiator

\begin{tabular}{|c|c|c|c|c|c|c|c|c|c|c|}
\hline & $\underline{\underline{\underline{p}}}$ & 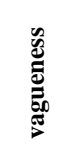 & 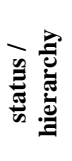 & 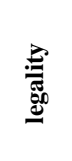 & 总 & 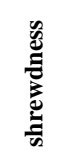 & 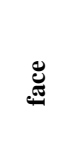 & $\frac{\overrightarrow{\mathrm{U}}}{\mathrm{E}}$ & $\begin{array}{l}\tilde{x} \\
\bar{\Xi} \\
\text { ป̄ }\end{array}$ & 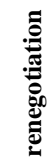 \\
\hline 1 & $43 \%$ & $3 \%$ & $7 \%$ & $3 \%$ & $3 \%$ & $0 \%$ & $0 \%$ & $10 \%$ & $20 \%$ & $3 \%$ \\
\hline 2 & $3 \%$ & $3 \%$ & $23 \%$ & $10 \%$ & $13 \%$ & $7 \%$ & $17 \%$ & $3 \%$ & $7 \%$ & $7 \%$ \\
\hline \multirow[t]{2}{*}{3} & $13 \%$ & $7 \%$ & $10 \%$ & $0 \%$ & $10 \%$ & $10 \%$ & $7 \%$ & $13 \%$ & $10 \%$ & $10 \%$ \\
\hline & $60 \%$ & $13 \%$ & $40 \%$ & $13 \%$ & $27 \%$ & $17 \%$ & $23 \%$ & $27 \%$ & $37 \%$ & $20 \%$ \\
\hline
\end{tabular}

The figures reflect that $60 \%$ of the sample ranked the importance placed on trust within their top 3 (selections of statements), and of these, $43 \%$ ranked trust as the statement that best describes the Chinese negotiator. Other significant percentages include the emphasis placed on the importance of status and hierarchy, which was selected by $40 \%$ of our respondents, whilst guanxi was selected by $37 \%$ of respondents. Rankings (based on frequency of selection) are represented in Table 2 below:

Table 2: Ranking summary

\begin{tabular}{c|l|c}
\hline Rank & Best describe Chinese behaviour & $\mathbf{\%}$ \\
\hline 1 & Trust & $60 \%$ \\
\hline 2 & Status/Hierarchy & $40 \%$ \\
\hline 3 & Guanxi & $37 \%$ \\
\hline 4 & Harmony & $27 \%$ \\
\hline 5 & Context & $27 \%$ \\
\hline 6 & Face & $23 \%$ \\
\hline 7 & Renegotiation & $20 \%$ \\
\hline 8 & Shrewdness & $17 \%$ \\
\hline 9 & Vagueness & $13 \%$ \\
\hline 10 & Legality & $13 \%$ \\
\hline
\end{tabular}

Questions (see Table 3) relating to experiences of Chinese negotiators' behaviour were posed. Respondents were asked to show their level of agreement with statements pertaining to this. Respondents agreed that Chinese negotiators have a strong sense of hierarchy (S2 - 4.57), a reserved nature, are not perceived to be judgmental and up-spoken (S3 - 4.13), value long term relationships (S14 - 4.48) and take time to foster relationships ( $\mathrm{S} 45$ - 3.97), place a high value on status (S22 - 4.31), are shrewd negotiators (S26 - 4.43), attach great value to business networks (S44 - 4.10), and are sensitive to how they are perceived by fellow negotiators (S47 - 4.00). A Cronbach item reliability test to affirm whether these statements grouped around each of these themes adequately represented the theme in question (Table 3). The high alpha indicates that the statements within the group are reliable in measuring these underlying themes.
Table 3. Summary of Cronbach's tests

\begin{tabular}{l|l|c}
\hline \multicolumn{1}{c|}{ Strain } & \multicolumn{1}{c|}{ Questions } & Alpha* \\
\hline Face & Q3, Q31, Q46, Q47 & 0,56 \\
\hline $\begin{array}{l}\text { Status and } \\
\text { Hierarchy }\end{array}$ & Q1, Q2, Q19, Q22 & 0,64 \\
\hline Guanxi & Q44, Q45 & 0,59 \\
\hline Trust & Q8, Q9, Q14, Q28 & 0,15 \\
\hline Vagueness & Q4, Q6, Q10, Q15, Q17, Q20, Q21, Q23 & 0,82 \\
\hline Shrewdness & Q10, Q11, Q12, Q13, Q16, Q25, Q26, Q40, & 0,84 \\
\hline $\begin{array}{l}\text { Contradictory } \\
\text { Behaviour }\end{array}$ & Q4, Q5, Q7 & 0,71 \\
\hline Harmony & Q3, Q14, Q33, Q34, Q35, Q39 & 0,42 \\
\hline Context & Q3, Q30, Q42 & 0,23 \\
\hline Inefficiency & Q11, Q12, Q18, Q19, Q25, Q43 & 0,68 \\
\hline $\begin{array}{l}\text { Long Term } \\
\text { Relationships }\end{array}$ & Q14, Q28, Q45 & 0,50 \\
\hline Legality & Q6, Q29 & 0,54 \\
\hline Holism & Q17, Q20, Q21 & 0,61 \\
\hline Renegotiation & Q7, Q12, Q25 & 0,80 \\
\hline * Romnd 2 del
\end{tabular}

* Rounded to 2 decimal places

An alpha rating below 0.5 was selected as the cut-off for the reliability test findings. The statements self-selected for the strains of trust (0.14), harmony (0.42) and context (0.23) are not deemed reliable in terms of the Cronbach test. In addition to Cronbach's tests conducted above, we decided to run a factor analysis as an objective method to establish whether there are any additional perceptions that could be identified. A principal component factor analysis was done to extract underlying constructs/factors in order to explain the profile of the statements as contained in question 6 of our questionnaire (Wegner, 2004; DeCoster, 2003). The Kaiser criterion was applied in order to determine which of the identified factors should be retained. In terms of the Kaiser criterion, all factors with an Eigen value of 1.0 or higher were retained Fourteen factors were retained (significant factors). A Varimax rotation strategy was used to ensure a set of factors where each variable loads high on one factor and very low on other factors. The objective is to ensure that each factor represents a different theme. The statements (instrument items) identified under each factor was analysed in order to label each of the factors appropriately. Collectively the 14 significant factors explain $87.31 \%$ of the total variation (of the original variables), and hence they capture the essence of the original variables quite well. Factor loadings measure the extent by which each of the variables/statements are correlated against the factors (i.e. the extent by which each of the factors explains the variables loaded onto that factor). Statements with a high factor loading can be used with more confidence to describe the factor concerned. We have decided to ignore statements with a factor loading of less than 0.5 in describing each of the factors. From our analysis of the instrument items loaded on the 14 factors above, we identified 8 themes which explain $62 \%$ of the total variance (Table 4 ). 
Table 4: Themes relating to hypothesis 1

\begin{tabular}{l|c|c}
\hline \multicolumn{1}{c|}{ Identified themes } & Factors & Explained variances \\
\hline Power & 1 & 27,81 \\
\hline Renegotiate positions & 2 & 9,57 \\
\hline Strategic ploys & 3 & 7,33 \\
\hline Value personal relations & 5 & 6,16 \\
\hline Legality & 8 & 3,69 \\
\hline Face & 11 & 2,83 \\
\hline Harmony & 12 & 2,60 \\
\hline Status & 13 & 2,22 \\
\hline Total Variance & & $\mathbf{6 2 , 2 1}$ \\
\hline
\end{tabular}

The statements loaded onto factors 4, 6, 9, 10 and 14 did not reveal any themes. As discussed in the literature review, reciprocity is closely linked to the concept of face. The selection of reciprocity to label this factor is supported by the high score attached to the reciprocity-specific statement (S27 - 0.8). The single, yet very dominant statement 22 (0.87) loaded onto this factor tests the degree of value placed by the Chinese on the status (age, gender and company position) of fellow negotiators. Status clearly stands out. The self-selected theme of 'hierarchy and status' (subjected to the Cronbach item reliability test and obtaining an alpha of 0.64) already contains statement 22. We decided not to separate this theme into two sub-themes called 'hierarchy' and 'status'.

\section{Findings on perceptions for proposition 1}

A number of themes identified through the factor analysis corresponded with some of the themes that were selfselected and subjected to the item reliability test. Where corresponding themes was found reliable (in terms of Cronbach) we examined the Cronbach questions in order to determine the perceptions held by our respondents (in such cases the corresponding factor was discarded). In addition, those themes that did not pass an item reliability test (trust and harmony), but that were identified through the factor analysis, were further scrutinized for applicability as a potential perception/theme. Factor 12, harmony, and factor 1 , trust, were two such themes that were analysed in this way.

Table 5 above denotes the 14 selected themes which together with their respective statements) forms the basis of the descriptive analysis undertaken against our sample. The aim is to identify the perceptions of South African's for each of the strains, and thereafter to compare the findings against Western perceptions as discussed in the literature review. Through this we tested proposition 1, namely, that SA business negotiators' perceptions of Chinese negotiation styles and behaviours are different from those held by Western business negotiators.
Table 5: Strains listed per source

\begin{tabular}{l|l|l}
\hline \multicolumn{1}{c|}{ Strains } & \multicolumn{1}{|c}{ Source } & \multicolumn{1}{c}{ Focus questions } \\
\hline Trust and Power & $\begin{array}{l}\text { Factor } \\
\text { Analysis }\end{array}$ & Q32, Q40, Q41, Q42, Q46 \\
\hline $\begin{array}{l}\text { Value Personal } \\
\text { Relations }\end{array}$ & $\begin{array}{l}\text { Factor } \\
\text { Analysis }\end{array}$ & Q28, Q39 \\
\hline Reciprocity & $\begin{array}{l}\text { Factor } \\
\text { Analysis }\end{array}$ & Q27, Q47 \\
\hline Harmony & $\begin{array}{l}\text { Factor } \\
\text { Analysis }\end{array}$ & Q33, Q34 \\
\hline Face & Cronbach & Q3, Q31, Q46, Q47 \\
\hline Status and & & Q1, Q2, Q19, Q22 \\
Hierarchy & Cronbach & Q44, Q45 \\
\hline Guanxi & Cronbach & Q10, Q11, Q12, Q13, Q16, Q25, \\
\hline Shrewdness & Cronbach & Q26, Q40, Q41, Q42, Q43, Q48 \\
\hline $\begin{array}{l}\text { Contradictory } \\
\text { Behaviour }\end{array}$ & Cronbach & Q4, Q5, Q7 \\
\hline Inefficiency & Cronbach & Q11, Q12, Q18, Q19, Q25, Q43 \\
\hline $\begin{array}{l}\text { Long-Term } \\
\text { Relationships }\end{array}$ & Cronbach & Q14, Q28, Q45 \\
\hline Legality & Cronbach & Q6, Q29 \\
\hline Holism & Cronbach & Q17, Q20, Q21 \\
\hline Renegotiation & Cronbach & Q7, Q12, Q25 \\
\hline
\end{tabular}

Although respondents were neutral on the issue whether the Chinese negotiators use their power to control the agenda, they did seem to somewhat agree that the Chinese are reluctant to reject proposals introduced through their counterparts. On the question of trustworthiness of the Chinese, South African's average response to trustworthiness was that there was some agreement (S32 3.39). This is further supported by S40 (2.23) that Chinese negotiators can be trusted not to employ dirty tricks to their own advantage (note that this statement was phrased in the reverse). These three aspects on their own do not test perceptions about three main elements of trust as evident from the literature review, namely, (a) the difficulty to gain/build the trust of the Chinese, (b) the initial distrust displayed by the Chinese negotiating counterpart, and (c) the fact that trust has an inherent importance for successful negotiations. In order to explore the perceptions on these three elements, we reverted to statements dealing with trust, which were not loaded on this factor. Our original discarded criteria set for trust (as per the Cronbach alpha reliability test) was used in this regard. Unlike the common perception as contained in academic literature (and as indicated in our literature review on trust), our respondents did not have a strong opinion (2.9) on whether the Chinese are distrustful of foreign negotiators, nor, that it is difficult to earn the respect and trust of the Chinese (2.83). These statements tend to fall within aspects (a) and (b) as mentioned above. Note that both these statements were phrased in the negative, and thus our respondents did not as an average agree with these statements. Trust (question 8) was rated by $60 \%$ of respondents as one of the top 3 statements that best describe the Chinese (the importance placed on trust between the negotiating parties - covering aspect (c) above). This clear recognition by our respondents that trust is important, tends to sway the perceptions held by South African's that they enjoy an above average, trustful 
relationship with the Chinese, although the direct perceptions interrogated through question 6 fails to support this. In summary, SA negotiators perceive Chinese negotiators to place a lot of importance on trustful relationships, but were neutral in regards to the difficulty as South African's to gain the respect and trust of the Chinese, and neutral in their perception on whether they perceive the Chinese to be trustworthy.

The mean SA response was to agree that the Chinese are interested in getting to know them on a more personal level (3.86). This corresponds strongly with Fang's (1999) proposition that the Chinese value personal relations. Interview data is similar. Chinese negotiators appeared to be more focused on the personal relationship with the counterpart, than the company he or she represented. Initially however, the status of the company plays a role, but this is readily replaced with an increased focus on a trust relationship with individuals of the company. Replacement of one foreign negotiator with another will hamper the negotiation process, because the trust relationship is established with the individual and not the firm. Regarding the perception of reciprocity, our sample responses were neutral concerning the obligation to return favours and gifts (S27 - 2.82). After some analysis of these responses, only $53 \%$ of our respondents indicated clear support for reciprocation in this manner. According to our literature review, gifts are an important component of the negotiation process. Responses to perceptions reflecting elements of face were on the whole in agreement, revealing that South Africans perceive the Chinese to be sensitive to how they are perceived (S47 - 4.00) and that the Chinese seldom explicitly reject proposals placed on the negotiation table (S46 - 3.66). The tendency not to reject proposals is related to the aspect of the Chinese wishing to save face of behalf of their negotiation counterparts. Our qualitative interviews made mention of the concept of face, as encountered when negotiating with the Chinese:

'They talk abut face all the time. You can hear them when they talk and when I've had English Chinese speaking people with me they have said 'no, they don't want to lose face'. In other words, it is a sign of respect for you and for them.

'They will bend over backwards because they want to keep face with you and make you look good in terms of what you are trying to do because at the end of the day if you look good, they look good'.

Cognizance of face by SA negotiators supports the literature review that emphasizes the importance that face plays. Table 6 below considers perceived importance of hierarchy and status.

South African perceptions of the high value attached to the status of the negotiator (in terms of age, gender and company position) revealed a strong favourable response (S22 - 4.31). Furthermore, strong agreement in response to the question that South African's perceive the Chinese to have a strong sense of hierarchy (S2 - 4.57) supports findings of Woo \& Prud'homme (1999). In addition, the emphasis placed on the importance of status and hierarchy was ranked by $40 \%$ of respondents within the top 3 statements that best describe Chinese negotiations.

\section{Table 6: Importance of hierarchy and status}

\begin{tabular}{c|l|c}
\hline Q6 & \multicolumn{1}{|c}{ Statements } & Mean \\
\hline S1 & $\begin{array}{l}\text { They seldom make decisions during meetings, and usually } \\
\text { refer back to a higher authority which is not at the } \\
\text { negotiation table }\end{array}$ & 3,52 \\
\hline S2 & They have a strong sense of hierarchy & 4,57 \\
\hline S19 & They take their time to make decisions & 3,25 \\
\hline S22 & $\begin{array}{l}\text { They attach a high degree of value to the status of the } \\
\text { negotiator (age, gender, company position) }\end{array}$ & 4,31 \\
\hline
\end{tabular}

South African's tend to agree in their perception (S44 4.10) that the Chinese place great value on business networks, and added to this, that the Chinese take time to foster relationships (S45 - 3.97). In support of this, 37\% of respondents in question 8 (as such being the $3^{\text {rd }}$ highest ranked perception) recognised the importance placed by the Chinese on business networks. These findings are in alignment with the perceptions found by Hutching (2003) during his study of Australian expatriate perceptions and confirm the findings by Horwitz et al. (2005). Overall, the responses revealed that South African's are neutral in their perceptions of the Chinese with regards to the use of strategies to gain negotiation advantage. Despite these findings, however, it is interesting to note that a direct statement testing the perception of shrewdness revealed high levels of agreement amongst the sample (S26 - 4.43). We investigated this anomaly further by comparing the perception of shrewdness (S26) with the perception that the Chinese use dirty tricks and ploys (S40). It was found on the whole that the high mean for shrewdness was in contrast to the low mean obtained of the perception that dirty tricks and ploys are used in negotiations. This perception may suggest a 'competitive shrewdness', without negotiators resorting to dirty or underhanded strategies rather than an under-handed connotation. It appears that the neutral perceptions of South Africans are in contrast to that of Westerner negotiators, where the literature suggests tricks and ploys are more pronounced where trust levels are low (Fang, 1999). Over 50\% of respondents gave top rankings to the importance the Chinese placed on trust. A combination of these two responses gives insight into the likelihood that the neutral position towards shrewdness is explained by the high awareness of trust, although this relationship has not been statistically proven.

\section{Long-term relationships}

The average response from our survey corresponds with Western perceptions set out in academic literature that Chinese negotiators place great value on harnessing longterm relationships and show interest in getting to know their negotiating counterparts. The average responses varied from agreement with the statement that the Chinese were interested in getting to know the other side on a more personal level (S28 - 3.86) and would commit time to foster such relationships (S45 - 3.97), and to strong agreement with the statement that they place importance on fostering 
long-term relationships (S14 - 4.48). Our interviewees also identified the importance of relationships built on trust. In order to establish these trust relationships it seems important that SA negotiators show an interest in and engage with their Chinese counterparts. This includes taking an interest in and being respectful of Chinese culture and traditions. From the perceptions analysed above (identified through Cronbach's Alpha and Factor Analysis), 6 themes of SA perceptions were identified as agreeing with those of Western negotiators (Table 7). Of these 6, the themes of status and hierarchy and long-term relationships can be considered to strongly agree with Western literature, indicating the high similarity of perceptions between South African's and Western cultures that negotiate with the Chinese. The remaining 8 themes reflected a neutral stance in comparison to Western perceptions.

\section{Table 7: Overall strain summary}

\begin{tabular}{l|c}
\hline \multicolumn{1}{c|}{ Strain } & (A)gree/(N)eutral/(D)isagree \\
\hline Trust & $\mathrm{A}$ \\
\hline Value Personal Relations & $\mathrm{A}$ \\
\hline Reciprocity & $\mathrm{N}$ \\
\hline Harmony & $\mathrm{N}$ \\
\hline Status and Hierarchy & $\mathrm{AA}$ \\
\hline Face & $\mathrm{A}$ \\
\hline Guanxi & $\mathrm{A}$ \\
\hline Shrewdness & $\mathrm{N}$ \\
\hline Contradictory Behaviour & $\mathrm{N}$ \\
\hline Inefficiency & $\mathrm{N}$ \\
\hline Long Term Relationships & $\mathrm{AA}$ \\
\hline Legal contracts & $\mathrm{N}$ \\
\hline Holism & $\mathrm{N}$ \\
\hline Renegotiation & $\mathrm{N}$ \\
\hline
\end{tabular}

(* AA denotes strongly agree)

With the high number of neutral outcomes, there is no overwhelming evidence to show those SA negotiators' perceptions of Chinese negotiation styles and behaviours are different from those held by Western business negotiators. Proposition 1 is not validated on the basis of our findings; in that SA business negotiators' perceptions are consistent with that of Western perceptions.

\section{Proposition 2 - Negotiator frustrations}

Proposition 2: South African negotiators do not share the same frustrations as Western business negotiators when dealing with Chinese counterparts. Respondents were asked to rank their top 3 frustrations, ranked from 1 (for highest) to 3 (the lowest), when negotiating with the Chinese. Each ranking was inverted, by subtracting its value from the integer 4 , in order for the most significant frustration to be highest ranked (3). Sixteen clusters were identified on the basis of key words or constructs in each response (Saunders et al., 2003). The weight of a cluster is determined by adding the weighting of each frustration listed within that particular cluster.

The language barrier and use of strategic tricks and ploys were jointly identified as the foremost frustrations experienced by our respondents). Although our literature review, based on previous Western research findings, reveals language barriers to be problematic, we did not interpret language barriers as a behavioural frustration. Other highly ranked frustrations include the Chinese tendency to renegotiate issues as well the tendency to draw out negotiations. Although not a top ranking, our respondents also experienced frustrations with hierarchical decision-making structures. Respondents also found some degree of frustration when confronted with the preoccupation of saving face.

These are mainly frustrations experienced by slow negotiations, festering as Western impatience, frustration experienced through perceived disrespect for legal rules, and perceived contradictory behaviour (Fang 1999). Our findings reveal that the length of negotiations and the tendency to revert back to renegotiation are consistent with Western impatience; and associated with Hofstede's fourth dimension, which describes a long term orientation in Chinese culture versus the relative short term orientation of Western cultures. Although indicated as separate categories in this research, should each of these frustrations ('renegotiations' with a count of 17 and, 'lengthiness of negotiations' with a count of 17) be combined, then this combined frustration would rate highest, confirming consistency between SA and Western negotiators over frustrations experienced through the slow nature of negotiations. Interestingly, Western research outcomes that labelled legal frustrations as prominent did not reflect with much weight in our rankings. Frustrations surrounding legal uncertainty received in fact a very low mention, thus we deduce that SA negotiators do not find legal uncertainty to be particularly frustrating, in contrast with that of Western negotiators. Contradictory behaviour did not feature as a frustration as listed by our respondents. Proposition 2 states that South African's do not share the same negotiation frustrations as Western business negotiators when dealing with their Chinese counterparts. Our findings reveal that SA negotiators tend to share two frustrations with Westerners (the slowness of negotiations and the shrewdness of the negotiators), and that in other areas Western frustrations do not apply to SA negotiators (legal frustrations and contradictory behaviour).

In light of these findings, there is not significant enough evidence to accept proposition two.

\section{Proposition 3 - South African socio-political influences}

\section{Proposition description}

Proposition 3: South African socio-political factors contribute positively towards the ability of SA negotiators to successfully negotiate with their Chinese counterparts. Respondents were asked to rate whether these specific aspects of being South African, captured in the 7 statements, had a positive influence on their ability to negotiate. There was no clear support for this proposition. The means for each statement fell within a band of 1.9 to 3.3 (from little to moderate influence). None of the aspects of the SA experience embodied in the statements were viewed as 
having a strong positive influence on the negotiation experience of South Africans. Our research did not clearly show that SA negotiators are positively influenced by their exposure to aspects such as the diversity of our country, workplace dynamics and the values of respect and tolerance enshrined in our constitution.

\section{Factors contributing to successful negotiations}

A single question asked the respondents to identify factors that made their negotiation endeavours a success. These responses were assessed and grouped according to themes on the basis of key words and constructs displayed by the responses. Four dominant themes contributing to the success of negotiations were identified (Table 8).

Table 8: Dominant themes contributing to successful negotiations

\begin{tabular}{l|c}
\hline \multicolumn{1}{c|}{ Dominant theme } & \% of respondents \\
\hline Persistence and Patience & $33 \%$ \\
\hline Relationship Building & $20 \%$ \\
\hline Cultural sensitivity and understanding & $20 \%$ \\
\hline Preparation & $17 \%$ \\
\hline
\end{tabular}

The priority placed on exhibiting patience in order to achieve successful negotiations is apt (Ghauri \& Fang, 2001). Our respondents also perceived the Chinese as placing great value on long-term relationships and social capital, which confirms the importance that Chinese negotiators place on building strong relationships. This supports the importance placed on guanxi and networks as a means of getting things done in China (Woo \& Prud'homme, 1999). It is therefore understandable that our respondents identified relationship building and cultural sensitivity as an important factor contributing to successful negotiations. It is important for foreigners to have a good understanding of and sensitivity for Chinese culture. This was highlighted in research done on the experiences of SA multinational firms in China (Horwitz et al., 2005) and elsewhere in Asia (Horwitz et al., 2006). Respondents also confirmed the importance of being well prepared and adopting a strategic approach before entering into negotiations. Good preparation is essential when dealing with negotiating counterparts with a very high work ethic and diligence in their preparation for negotiation (Graham \& Lam, 2003). Both Chinese and Western negotiators see preparation as key to effective negotiation (Sheer \& Chen, 2003). Semi-structured interview responses supported the importance placed on preparation.

\section{Most valuable lessons learned}

Respondents were asked to rank their top 3 most valuable lessons, ranked from 1 (for highest) to 3 (the lowest). In order to represent weightings we inverted each individual ranking by subtracting each from the integer 4 . Our initial labeling process identified 25 such themes, at a low level of focus. These themes were compared and regrouped into 11 broader clusters. Note that a number of lessons identified (e.g. 'the focus on detail', 'be goal orientated', 'shake their hands look them in the face') could not be clustered due to an infrequent rate of mentioning. In summary, the weighting of the different clusters are visually depicted in Figure 3 below.

A number of the lessons represented here can be explained by the literature review. For example, one would expect people who engage with a culture which places huge importance on hierarchy and status, to identify respect as an important lesson. The same can be said of face and language. Patience during the negotiation process was identified as the most important lesson for our respondents. This is not surprising, particularly in that they perceived long drawn out negotiations as a frustration in negotiating. The need to display traits of trustworthiness and integrity is important (Ting-Toomey \& Kurogi, 1998:206). This confirms the popular view that trust is earned through consistent behaviour over a long period of time (Fang, 1999). The benefit of establishing such a trust relationship based on integrity is that Chinese negotiators might adopt a more cooperative negotiation style and refrain from using strategic tricks and ploys, as found in competitive negotiation processes aimed at win-lose outcomes (Fang, 1999). The relatively low ranking given to lessons related to networks, relationships and harmony, notwithstanding the fact that relationship building was raised as an important success factor was surprising. This ostensible discrepancy may be explained by the nature of the negotiation style used by our respondents. If they deploy an integrative negotiation style focused on maintenance of long-term relationships, then networking and relationship building could be regarded as inherent behaviour familiar to SA negotiators. 


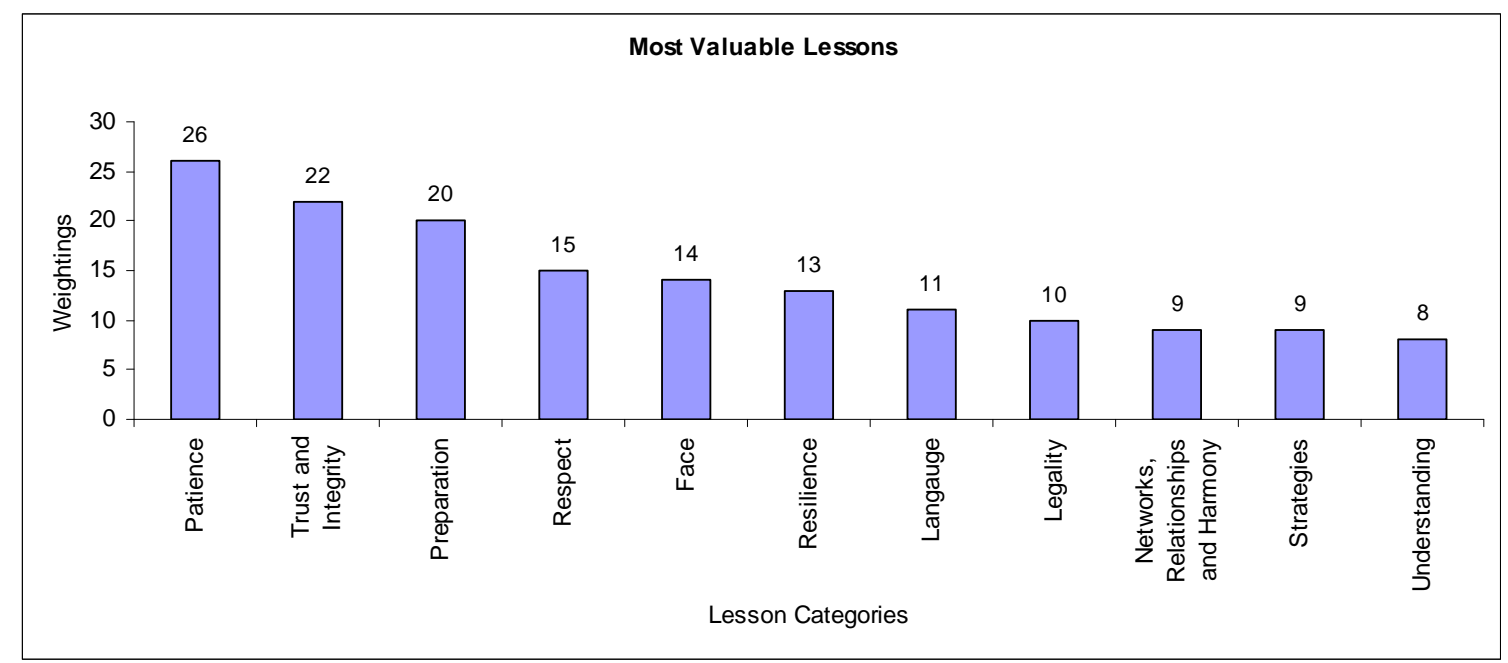

Figure 3: Most valuable South African negotiator lessons learned

\section{Conclusions}

Our research reveals that the perceptions about Chinese negotiation behaviour and styles are fairly similar to that of Westerners. South African negotiators perceive the Chinese negotiators to value status, respect hierarchical decisionmaking, and appreciate long-term relationships. In addition, the perceptions on the importance of trust, guanxi and face were strongly evident in our research. It was found that South Africans appreciate the honesty and integrity, the importance placed on relationships as well as the work ethic and persistence displayed by Chinese negotiators. It is thus not surprising South Africans identified relationship building as a key success factor during negotiations. Miles (2003) concludes that a focus on relationship building will bring long run negotiation benefits. Our research also showed that SA negotiators' frustrations did not differ substantially from that of Westerners. The time taken in fostering and developing relationships, renegotiating and revisiting issues during negotiations, and in general the drawn out or prolonged nature of negotiations with Chinese business people proved to be one of the main frustrations. Strategic planning, resilience and patience is required to achieve successful negotiations (Ghauri \& Fang, 2001; Van der Wath 2004). The competitive nature of Chinese negotiators, manifesting itself through the use of strategic tricks and ploys, proved to be a large frustration for South Africans, which is similar to that experienced by Western negotiators. These strategic tricks and ploys of the Chinese indicate the use of a competitive negotiation style when dealing with South Africans. However, the perception that the Chinese value long-term relationships reflects a more cooperative/integrative negotiation style. This may confirm Fang's (1999) view of Chinese negotiators as being both 'Confucian gentleman' and ultimate strategist (exhibiting contradictory behaviour). In the context of this combined co-operative and competitive style of negotiation, the advice of Fang (1999) and Staber (2006) is not to directly engage at a strategic level, but to rather build a trustful relationship and social capital through personal integrity and a cooperative negotiation style.

The above mentioned similarities between SA and Western negotiators seem to indicate that the Chinese employ the same negotiation behaviour and styles when negotiating with these groups. Certain aspects of being South African had a moderate influence on the ability to negotiate successfully with the Chinese. Our respondents' exposure to aspects such as ubuntu and 'spirit of reconciliation' was identified as having little influence. We find this somewhat surprising as we expected the exposure to cultural diversity to lead to greater sensitivity and understanding of Chinese negotiation behaviour, potentially resulting in successful negotiations. We anticipated South Africans to have greater cultural alignment with the Chinese, due to their exposure to the collectivistic philosophy known as ubuntu, which is underpinned by relationships and social harmony. Our literature review indicates that the greater the cultural alignment, the better the chance of achieving successful negotiations (Sheer \& Chen, 2003). These results could possibly be explained by some of the limitations in our research, though the Chinese way of doing business does not readily correspond with Western models of corporate governance and behaviour (Christianson, 2006).

\section{References}

Anderson, T. 1992. 'Step into my parlour: A survey of strategies and techniques for effective negotiation', In Lewicki, Saunders, Minton \& Barry, 2003. Negotiation: Readings, exercises, and cases. Pp.122-130.

Bates, H. \& Adams, D. 2003. 'Analysis and comparison of the assistance provided by South African governmental and non-governmental agencies to South African organizations exporting to the Peoples Republic of China'. Unpublished research report submitted as part of a Masters in Business Administration degree at the Graduate School of Business, University of Cape Town, Cape Town.

Bird, A. \& Metcalf, L. 2003. 'Integrating twelve dimensions of negotiation behavior and Hofstede's work-related values: A six country comparison'. Paper delivered at the $7^{\text {th }}$ International Conference on Global Business and Economic Development, Thailand. [online] URL: http://blake montclair.edu/ cibconf/conference/DATA/The me4/Usa1.pdf. Accessed 11 November 2004. 
Booysen, L. 2001. 'The duality in South African leadership: Afrocentric or Eurocentric', South African Journal of Labour Relations, Spring:36.

Brett, J.M. 2000. 'Culture and negotiation', International Journal of Psychology, 35(2):97.

Buttery, E.A. \& Leung, T.K.P. 1996. 'The difference between Chinese and Western negotiations', European Journal of Marketing, 32(1):374.

Coggin, W.O. \& Coggin. B.F. 2001. 'So you want to work in China’, Technical Communication, 48(4):389.

Christianson, D. 2006. 'Rapacious dragon, friendly tiger,' Business in Africa, May: 48-50.

Davies, M. 2004. 'Engaging the dragon economy'. In Le Pere, G. (Ed.). China through the third eye. Midrand: Institute for Global Dialogue, pp. 104-105.

Davies, M. 2007. 'An inevitable partnership', Focus, 45:1821. Helen Suzman Foundation.

DeCoster, J. 2003. 'An overview of factor analysis'. [online] URL: http://www.bama.ua.edu/ pysc/factor.pdf. Accessed 24 November 2004.

Fang, T. 1999. Chinese business negotiating style. California: SAGE Publications.

Gesteland, R.R. 1997. 'Cross-cultural business behaviour.' [online] URL: http://www.zmk.unifreiburg.de/ss2000/texts/gesteland htm. Accessed 3 October 2004.

Ghauri, P.N. \& Fang, T. 2001. 'The Chinese business negotiation process: A socio-cultural analysis', Journal of World Business, 37:303-325.

Graham, J.L. \& Lam, N.M. 2003. 'The Chinese negotiation', Harvard Business Review, October:82.

Herbig, P. 2004. 'Cross-cultural negotiations: The dimension of time in negotiations'. Unpublished notes. [online]

URL:http://www.tristate.edu/faculty/herbig/pahccn10 htm.

Accessed 17 November 2004.

Hofstede, G. et al. 2002. 'What goals do business leaders pursue. A study in fifteen countries', Journal of International Business Studies, 33:785-803.

Horwitz, F., Ferguson, M., Rivett, I. \& Lee, A. 2005. 'An Afro-Asian nexus: South African multinational firm experiences in the Chinese labour markets - key focus areas, South African Journal of Business Management, 36 (3):2940.

Horwitz, F., Chan, T.H., Quazi, H., Nonkwelo, C., Roditi, D. \& Van Eck, P. 2006. 'Human resource strategies for managing knowledge workers: An Afro-Asian comparative analysis', International Journal of Human Resource Management, 17(5): 775-811.

Hutching, K. 2003. 'Family, face, and favours: Australian expatriates' experiences in adjusting to accepted business conventions in China.' [online] URL: http://web.cbs.dk/departments/int/seminars/KH070503.doc. Accessed 3 October 2004.

Kumar, R. \& Worm, V. 2003. 'Social capital and the dynamics of business negotiations between the Northern Europeans and the Chinese', International Marketing Review, 20(3):262.

Leung, S. $2003 . \quad$ 'China.' [online] URL:http://www.ncl.ac.uk/ecls/assets/files/CCC-China.pdf. Accessed 8 October 2004.

Lewicki, R.J., Saunders, D.M., Minton, J.W. \& Barry, B. (Eds.). 2003. Negotiation: Readings, exercises, and cases. New York: McGraw-Hill.

Li , J., Wang, L. \& Fischer, K.W. 2003. 'The organization of Chinese shame concepts'. [online]URL: http://www.gse.harvard.edu/ ddl/articlesCopy/ShameRevisn FinalFigs.pdf. Accessed 24 November 2004.

Martin, D., Mayfield, J., Mayfield, M. \& Herbig, P. 1998. 'International negotiations: An entirely different animal'. In Lewicki, R.J., Saunders, D.M., Minton, J.W. \& Barry, B. (Eds.). 2003. Negotiation: Readings, exercises, and cases. New York: McGraw-Hill. Pp.340-354.

Metcalf, L., Bird, A., Peterson, M., Shankarmahesh, M. \& Lituchy, T. 2007. 'Cultural influences in negotiations', International Journal of Cross Cultural Management, 7(2): 163-164.

Miles, M. 2003. 'Negotiating with the Chinese: Lessons from the field', Journal of Applied Behavioral Science, 39(4):453.

Naranjo, D.A. 2001. 'Mediating in a highly diverse and volatile society'. [online] URL: http://www.attorneymediators.org/diverse html. Accessed 23 November 2004.

Organization for Economic Co-operation and Development. 2003 'Asia and China Programmes Annual Report 2003'. [online] URL: http://www.oecd.org.dataoecd. Accessed 22 July 2008.

O'Shea, B. 2002. 'China embraces the world markets'. Address delivered on 28 November 2002. Available [online] http://www.dfat.gov.au/publications/catalogue/china/Hunt_a nd_Hunt_speech_Melbourne_26_11_02.html. Accessed 18 November 2004.

Poulson, C. 2000. 'Shame: the master emotion?' [online]. URL:

http://www.dfat.gov.au/publications/catalogue/china/Hunt and Hunt speech Melbourne. Accessed 18 November 2004. 
Rijamampianina, R. \& Maxwell, T. 2002. 'Towards a more scientific way of studying multicultural management', South African Journal of Business Management, 33(3):17.

Saunders, M. Lewis, P. \& Thornhill, A. 2003. Research methods for business students. $3^{\text {rd }}$ Edition. Essex: Pearson Education Limited.

Sheer, V.C. \& Chen, L. 2003. 'Successful Sino-Western business negotiation: Participants' accounts of national and political cultures', Journal of Business Communication, 40(1):50.

Smith, M. 2000. 'International business negotiations: A comparison of theory with perceived reality' [online] URL: http://www.findarticles.com. Accessed 24 September 2004.

Staber, U. 2006. 'Social capital processes in cross-cultural management', International Journal of Cross Cultural Management, 6(2):189-203.

Tan, J.S. \& Lim, E.N.K. 2003. Strategic negotiation across cultures. Singapore: McGraw-Hill.

Taylor, E. 2002. 'Negotiating China' [online] URL: http://www.davis.ca/publications/2002-

03_negotiating_china.pdf. Accessed 3 October 2004.

Ting-Toomey, S. 1999. Communicating across cultures. Guilford Press, New York [online] URL: http://personal.anderson.ucla.edu/richard.goodman/c4web/ Mindful.htm. Accessed 24 November 2004.

Ting-Toomey, S. 1992. 'Cross-cultural face-negotiations: An analytical overview.' [online] URL: http://www.cic.sfu.ca/forum/ting-goo.htm. Accessed 25 September 2004.

Ting-Toomey, S. \& Kurogi, A. 1998. 'Facework competence in intra-cultural conflict: An updated facenegotiation theory', International Journal of Intercultural Relations, 22:187-225.

Trompenaars, F. \& Hampden-Turner, C. 1997. Riding the waves of culture - Understanding cultural diversity in business. London: Nicholas Brealey Publishing.

Van der Wath, K. 2004. Doing business in China, The Beijing Axis:153-163, 197-199.

Wegner, T. 2004. 'Quantitative research methodology with emphasis on survey sampling design, Part 2.” Unpublished notes.

World Bank Group. 2002. 'China data Profile' [online]. URL: http://devdata.worldbank.org.external/selected country. Accessed 20 July 2004.

Woo, H.S. \& Prud'homme, C. 1999. 'Cultural characteristics prevalent in the Chinese negotiation process', European Business Review, 99(5):313.
Yueh, L. \& Davies, H. 2004. 'China dreams', Management Today, March:44. 